Revista Brasileira de Agricultura Irrigada v.13, no.3, p. 3487 - 3497, 2019

ISSN 1982-7679 (On-line)

Fortaleza, CE, INOVAGRI - http://www.inovagri.org.br

DOI: $10.7127 /$ rbai.v13n301085

Protocolo 1085.19 - 07/05/2019 Aprovado em 18/06/2019

\title{
CULTIVO ORGÂNICO DA BANANEIRA 'BRS TROPICAL' SOB IRRIGAÇÃO E USO DE COBERTURA ORGÂNICA NO SOLO
}

\author{
Maurício da Silva Amorim ${ }^{1}$, Eugênio Ferreira Coelho², Diego Magalhães de Melo $^{3}$, Damiana Barros
} Lima $^{4}$, Lenilson Wisner Ferreira Lima ${ }^{5}$

\begin{abstract}
RESUMO
A ideia central do cultivo orgânico de alimentos é adotar técnicas de cultivo mais sustentáveis, que permitam o uso mais racional dos recursos e a conservação do agrossistema. O objetivo desse trabalho foi estudar os efeitos da condução orgânica e do uso de cobertura morta sobre os atributos físicoquímicos do solo e avaliar o uso de níveis de irrigação e de cobertura morta no desempenho da bananeira 'BRS Tropical'. Adotou-se um delineamento experimental em blocos casualizados, com seis tratamentos e quatro repetições, em esquema fatorial $3 \times 2$, com parcelas subdivididas no espaço, sendo três níveis de irrigação baseados na evapotranspiração da cultura (ETc) nas parcelas: L1 (100\% ETc); L2 (75\% ETc) e L3 (50\% ETc) e o uso de cobertura morta (com e sem uso) no solo, na forma de restos culturais de bananeira, nas subparcelas. Os efeitos da condução orgânica e cobertura morta sobre os atributos físico-químicos do solo foram avaliados no tempo. Durante o cultivo foram registrados aumentos na macroporosidade e porosidade total do solo. O uso de cobertura morta influenciou positivamente a disponibilidade de água, conteúdos de fósforo, potássio, cálcio e magnésio, acidez potencial e teor de matéria orgânica. A produtividade e a qualidade dos frutos da 'BRS Tropical' não foram influenciadas pela aplicação de cobertura morta ou pela redução da lâmina de irrigação em até $50 \%$.
\end{abstract}

Palavras-chave: bananicultura orgânica, Musa spp, qualidade do solo.

\section{ORGANIC CULTIVATION OF BANANA ' BRS TROPICAL ' UNDER IRRIGATION AND USE ORGANIC SOIL COVER}

\footnotetext{
ABSTRACT

${ }^{1}$ Engenheiro agrônomo, Doutorando em Genética e Biologia Molecular, Universidade Estadual de Santa Cruz, Ilhéus, Bahia, Brasil. E-mail: m.s.amorim@ hotmail.com;

${ }^{2}$ Engenheiro agrícola, Doutor em Engenharia de Irrigação, Pesquisador A na Embrapa Mandioca e Fruticultura, Cruz das Almas, Bahia, Brasil. E-mail: eugenio.coelho@embrapa.br;

${ }^{3}$ Engenheiro agrônomo, Doutorando em Engenharia Agrícola, Universidade Federal do Recôncavo da Bahia, Cruz das Almas, Bahia, Brasil. E-mail: engdmmelo@gmail.com;

${ }^{4}$ Engenheira agrônoma, Doutoranda em Engenharia Agrícola, Universidade Federal do Recôncavo da Bahia, Cruz das Almas, Bahia, Brasil. E-mail: damibarros@ hotmail.com;

${ }^{5}$ Engenheiro agrônomo, Doutorando em Engenharia Agrícola, Universidade Federal do Recôncavo da Bahia, Cruz das Almas, Bahia, Brasil. E-mail: lenilsonlimaagro@gmail.com;
} 
The central idea of organic farming is to adopt more sustainable cultivation techniques, which allow better rational use of resources and conservation of the agrissystem. The objective of this work was to study the effects of organic conduction and the use of mulch on soil physicochemical attributes and to evaluate the use of irrigation levels and mulch in the performance of Banana ' BRS Tropical '. A randomized block design was adopted, with six treatments and four replications in a 3x2 split-plot factorial scheme. Three irrigation levels based on crop evapotranspiration (ETc) in were in the main plots: L1 (100\% ETc); L2 (75\% ETc) and L3 (50\% ETc) and the use of mulch (with and without) on the soil, as banana residues in subplots. The effects of organic cultivation and mulch on soil physicochemical attributes were evaluated in time. During cultivation, increases in macroporosity and total soil porosity were recorded. The use of organic mulch influenced positively the availability of water, phosphorus, potassium, calcium and magnesium content, potential acidity and organic matter content. The productivity and quality of the 'BRS Tropical ' fruits were not influenced by the application of organic mulch or by the reduction of the irrigation depth in up to $50 \%$.

Keywords: banana organic production, Musa spp., soil quality.

\section{INTRODUÇÃO}

Dentre os países produtores de banana no Mundo destacaram-se no ano de 2017, a Índia, China, Indonésia, Brasil e o Equador, em ordem de participação na produção mundial, respectivamente (FAO, 2019). Neste mesmo ano, o Brasil alcançou produtividade média de 14,34 $\mathrm{t} \mathrm{ha}{ }^{-1}$ com produção de 6.675.100 toneladas, em uma área colhida de 465.434 hectares (IBGE, 2018).

Uma pequena parte desse mercado, é representada por frutas originadas de sistemas conhecidos como orgânicos, ecológicos ou sustentáveis (ROEL, 2016). O mercado de alimentos orgânicos é um nicho promissor e em expansão no Brasil e no Mundo (SANTOS et al., 2013; VEIRA et al., 2016).

As frutas produzidas nesse tipo de sistema têm apresentado valor diferenciado em função da demanda crescente e da valorização dos produtos obtidos de forma mais sustentável. Esse cenário tem incentivado os produtores, principalmente os pequenos bananicultores, que veem no cultivo orgânico uma oportunidade de obter rentabilidade de forma mais saudável (BORGES et al., 2015; ARAÚJO et al., 2016).

Por outro lado, para que sejam obtidas produtividades elevadas, nesse tipo de agrossistema, torna-se necessário tomar uma série de cuidados para garantir condições de cultivo compatíveis com a produção desejada, tendo em vista as limitações relacionadas ao uso de tecnologias previstas nas normativas brasileiras para esse tipo de sistema de produção (BRASIL, 2003; 2011; 2014).

Na produção orgânica é essencial adotar medidas que previnam problemas ou otimizem o uso de recursos. São exemplos o plantio de variedades melhoradas geneticamente, visando produtividade e tolerância a fitopatógenos, como a bananeira do tipo maçã 'BRS tropical' (SILVA et al., 2013; ARANTES et al., 2017; WEBER et al., 2017), o uso racional da irrigação (COELHO; SILVA, 2016; BEZERRA et al., 2017) e o reaproveitamento de resíduos do cultivo na forma de cobertura do solo (SEDIYAMA et al., 2015; BORGES et al., 2015; SOUZA; BORGES et al., 2016).

O uso criterioso dos recursos naturais também é importante, tanto em nível ambiental, como em nível econômico. Nesse contexto o uso racional da irrigação pode promover incremento da rentabilidade seja pela economia de água, energia elétrica, redução da dos gastos com manutenção da rede hidráulica, necessidade de mão de obra ou mesmo pela aplicação da água poupada em novas áreas irrigadas e em outras atividades dentro da propriedade agrícola (FRIZZONE, 2007; ARAÚJO et al., 2016).

Em sinergia, a aplicação dos resíduos vegetais pode ajudar a proteger o solo, atenuar o crescimento de ervas invasoras, conservar água na rizosfera, potencializar a atividade biológica no solo, melhorar a ciclagem de nutrientes, com melhoria da fertilidade do solo no tempo (RESENDE et al., 2005; BORGES et al., 2015; COELHO et al., 2016). 
O objetivo desse trabalho foi estudar os efeitos da condução orgânica e do uso de cobertura morta sobre os atributos físicoquímicos do solo e avaliar o uso de níveis de irrigação e do uso da cobertura morta no desempenho da bananeira 'BRS Tropical'.

\section{MATERIAL E MÉTODOS}

O experimento foi realizado nos campos experimentais da Embrapa Mandioca e Fruticultura, situada no município de Cruz das Almas - BA $\left(12^{\circ} 66^{\prime} \mathrm{S} ; 3^{\circ} 15^{\prime} \mathrm{W} ; 225 \mathrm{~m}\right.$ de altitude). O clima da região é classificado como úmido a subúmido, com uma pluviosidade média anual de $1.143 \mathrm{~mm}$.

O solo da área experimental foi classificado como Latossolo Amarelo Distrocoeso (SANTOS et al., 2018). Os atributos físico-hídricos, avaliados no início do experimento, para a profundidade $0-0,30 \mathrm{~m}$ foram: densidade do solo $1,73 \mathrm{~kg} \mathrm{dm}^{-3}$; umidade a $-10 \mathrm{kPa} 0,26 \mathrm{~cm}^{3} \mathrm{~cm}^{-3}$; e umidade a $-1500 \mathrm{kPa}$ de $0,17 \mathrm{~cm}^{3} \mathrm{~cm}^{-3}$. A avaliação inicial dos atributos químicos do solo revelou valores de $\mathrm{pH}, \mathrm{P}, \mathrm{K}, \mathrm{Ca}, \mathrm{Mg}, \mathrm{H}$, $+\mathrm{Al}$ e teor de matéria orgânica (MO) próximos a: 5,98; $12,00 \mathrm{mg} \mathrm{dm}^{-}$ 3; 0,$12 ; 2,22 ; 1,11 ; 1,55 \mathrm{cmol}_{\mathrm{c}} \mathrm{dm}^{-3}$ e $1,68 \mathrm{~g} \mathrm{~kg}^{-}$ ${ }^{1}$, respectivamente.

A cultura estudada foi a da bananeira (Musa sp.), cultivar BRS Tropical. No início do experimento, em julho de 2010, o pomar encontrava-se estabelecido e no início do sexto ano de produção. O espaçamento adotado no plantio foi de $3,0 \times 2,5 \mathrm{~m}$, com densidade de plantio calculada em 1.333 plantas $\mathrm{ha}^{-1}$. Durante o cultivo o controle das ervas invasoras foi realizado por roçagem manual.

A irrigação foi efetuada por microaspersão, com uma linha lateral entre duas fileiras de plantas, com emissores de vazão $48 \mathrm{~L} \mathrm{~h}^{-1}$, dispostos em faixa contínua, espaçados de $3,80 \mathrm{~m}$.

O experimento foi conduzido seguindo as diretrizes recomendadas para o cultivo orgânico no Brasil (BRASIL, 2003; 2011; 2014). Foi realizada adubação de cobertura trimestral com aplicação a lanço de torta de mamona e fosfato de rocha do tipo Gafsa. Fezse fertirrigação com biofertilizante tipo Vairo (VAIRO et al., 1996).
O biofertilizante foi produzido em meio anaeróbico utilizando-se $40 \mathrm{~L}$ de esterco bovino, $1 \mathrm{~kg}$ de farinha de ossos, $1 \mathrm{~kg}$ palha de bananeira picada e $80 \mathrm{~L}$ de água. O material sobrenadante foi aplicado 30 dias após sua produção. Realizou-se fertirrigação a cada 20 dias, com aplicação de biofertilizante equivalente a $1 \mathrm{~L}_{\text {planta }}{ }^{-1}$.

Adotou-se o delineamento experimental em blocos casualizados, com seis tratamentos e quatro repetições em um esquema de parcelas subdivididas, sendo três laminas de irrigação nas parcelas: L1 (irrigação com 100\% da Evapotranspiração de cultura-ETc); L2 (irrigação com $75 \%$ da ETc) e L3 (irrigação com $50 \%$ da ETc) e dois níveis de cobertura do solo nas subparcelas: Nível 1- com cobertura morta; e Nível 2 - sem cobertura morta para avaliação do desempenho das plantas.

Para avaliação dos atributos físicoquímicos do solo foi adotado um delineamento em blocos casualizados com parcelas subdivididas no espaço e no tempo. Para tanto, foram consideradas as condições adotadas para avaliação do desempenho das plantas aos 0 , 200 e 400 dias após o transplantio (DAT) para os atributos físicos e 0 e 400 DAT para os atributos químicos.

A irrigação foi feita com base na evapotranspiração de referência estimada pela equação modificada de Penman-Monteith conforme Allen et al. (1998), a partir de dados obtidos em Estação Meteorológica automática localizada à $200 \mathrm{~m}$ do experimento e coeficientes de cultura recomendados por Coelho et al. (2003). Adotou-se a eficiência de $90 \%$ para o sistema de irrigação e coeficiente de localização igual a 1.

No intervalo de outubro de 2010 a abril de 2011 ocorreram às irrigações, a precipitação nesses meses foi, com exceção de dezembro de 2010 e abril de 2011, inferior a $80 \mathrm{~mm}$ mês $^{-1}$. Nos meses em que a precipitação foi acima de $120 \mathrm{~mm}$ mês $^{-1}$ dispensou-se o uso da irrigação.

A diferenciação das lâminas de irrigação foi realizada por meio de registros de gaveta instalados no início das linhas de derivação correspondentes a cada tratamento. $\mathrm{O}$ monitoramento da umidade do solo foi realizado antes das irrigações, por meio da 
técnica da Reflectometria no Domínio do Tempo (TDR). Foram utilizadas sondas de TDR instaladas a $0,30 \mathrm{~m}$ de profundidade entre o pseudocaule e o microaspersor.

A cobertura morta foi obtida por meio do reaproveitamento de resíduos culturais de pomares de bananeira adjacentes a área experimental. A cobertura foi espalhada sobre o solo de modo a formar uma camada de, aproximadamente, $0,10 \mathrm{~m}$ sobre sua superfície, no início do ciclo de produção, com reposição da cobertura morta a cada 3 meses. $O$ solo que não recebeu cobertura morta recebeu apenas a roçagem manual e as adubações de cobertura.

Durante o ciclo da cultura foram retiradas amostras de solo para avaliar os atributos físico-hídricos e químicos do solo nos diferentes tratamentos. As amostragens foram feitas em julho de 2010 e em janeiro e julho de 2011, meses correspondentes ao início, meio e final do ciclo, para avaliar os atributos físicos e químicos do solo nos diferentes tratamentos. As análises físico-químicas foram realizadas conforme metodologia da EMBRAPA (1997).

Para as análises físicas, foram coletadas 36 amostras indeformadas, dentro de cada subparcela nas profundidades de $0-0,20$ e 0,20 $0,40 \mathrm{~m}$, com auxílio de anéis com volume conhecido inseridos em trado tipo Uhland. Foram avaliados os atributos porosidade total, macroporosidade, microporosidade e densidade do solo. Para determinação das análises químicas: $\mathrm{pH}, \mathrm{P}, \mathrm{K}, \mathrm{Ca}, \mathrm{Mg}, \mathrm{H}+\mathrm{Al}$ e teor de matéria orgânica, foram coletadas 36 amostras deformadas, dentro de cada subparcela, nas profundidades de 0-0,20 e 0,20$0,40 \mathrm{~m}$, com auxílio de um trado do tipo Holandês.

Ao final do ciclo foram selecionadas quatro plantas úteis em cada subparcela experimental para determinação do número de pencas, número de frutos por cacho, massa do cacho e da produtividade de cachos. A produtividade foi calculada como o produto da massa média de cachos pela densidade de plantio.

Foram realizadas análises físicoquímicas a partir dos frutos da $2^{\circ}$ penca de cada cacho colhido, com base nos métodos descritos por IAL (2005). O diâmetro e o comprimento do fruto foram obtidos com uso de uma fita métrica graduada em $\mathrm{mm}$, obtendo-se o diâmetro a partir da circunferência da região mediana do fruto. O comprimento foi obtido, medindo-se a curvatura externa de cada fruto. Uma balança de precisão $0,0001 \mathrm{~kg}$ foi usada para pesagem da penca, dos frutos e das polpas para encontrar a porcentagem de água e de massa seca da polpa.

As análises químicas foram realizadas a partir de cerca de $5 \mathrm{~g}$ da polpa da fruta. As amostras foram pesadas em uma Placa de Petri e levadas para estufa a $70^{\circ} \mathrm{C}$ por $48 \mathrm{~h}$, procedendo-se em seguida nova pesagem para determinar a umidade. Os Sólidos Solúveis Totais (SST) foram obtidos com o uso de um Refratômetro portátil, sendo os resultados encontrados em percentual de açúcares totais e expressos como ${ }^{\circ}$ Brix. Para determinar a Acidez Total Titulável (ATT), pesou-se um grama da amostra homogeneizada em um Becker, $\operatorname{logo}$ após, foi acrescentado água destilada até o volume final de $40 \mathrm{ml}$ e adicionado em cada Becker uma gota de fenolftaleína (1\%). A solução final foi titulada com o uso de um dosímetro, onde foi adicionado Hidróxido de Sódio $(0,1 \mathrm{~N})$ até a cor da solução ficar ligeiramente rosada. $\mathrm{O}$ pH foi determinado com um pHmetro de bancada. A partir da relação entre Sólidos Solúveis Totais e Acidez Total Titulável, calculou-se o índice de maturação dos frutos (SST/ATT).

Os dados obtidos foram submetidos à análise de variância. As médias de cada tratamento comparadas pelo teste de Tukey a $5 \%$ de probabilidade.

\section{RESULTADOS E DISCUSSÃO}

A análise de variância revelou que ocorreram efeitos isolados das lâminas de irrigação e da cobertura morta apenas sobre a variável número de frutos por penca. Indicando que a redução da lâmina em até 50\% (1.570,70 $\mathrm{mm}$ ciclo $^{-1}$ ) ou o uso da cobertura morta não influenciaram significativamente a produtividade de cachos da BRS Tropical (Tabelas 1 e 2). 


\section{CULTIVO ORGÂNICO DA BANANEIRA 'BRS TROPICAL' SOB IRRIGAÇÃO E USO DE COBERTURA} ORGÂNICA NO SOLO

Tabela 1. Variáveis de produção da bananeira 'BRS Tropical' sob diferentes lâminas de irrigação em um Latossolo Amarelo no município de Cruz das Almas - BA.

\begin{tabular}{ccccc}
\hline $\begin{array}{c}\text { Lâminas } \\
(\% \mathrm{ETc})\end{array}$ & $\begin{array}{c}\text { Número de } \\
\text { Pencas } \\
\text { (unidade) }\end{array}$ & $\begin{array}{c}\text { Número de } \\
\text { Frutos } \\
\text { (unidade) }\end{array}$ & $\begin{array}{c}\text { Massa do cacho } \\
(\mathrm{kg})\end{array}$ & $\begin{array}{c}\text { Produtividade de } \\
\text { cachos } \\
\left(\mathrm{Mg} \mathrm{ha}^{-1}\right)\end{array}$ \\
\hline L1 $(100 \%)$ & 7,0 & $116 \mathrm{ab}$ & 13.24 & 17,65 \\
L2 $(75 \%)$ & 6,9 & $124 \mathrm{a}$ & 12,73 & 16,97 \\
L3 $(50 \%)$ & 7,1 & $109 \mathrm{~b}$ & 11,90 & 15,86 \\
\hline
\end{tabular}

Médias seguidas das mesmas letras não diferem entre si pelo teste de Tukey a 5\% de significância.

Tabela 2. Variáveis de produção da bananeira 'BRS Tropical' sob cobertura morta (CC) e sem cobertura (SC) em um Latossolo Amarelo no município de Cruz das Almas - BA.

\begin{tabular}{ccccc}
\hline Cobertura do solo & $\begin{array}{c}\text { Número de } \\
\text { Pencas } \\
\text { (unidade) }\end{array}$ & $\begin{array}{c}\text { Número de } \\
\text { Frutos } \\
\text { (unidade) }\end{array}$ & $\begin{array}{c}\text { Massa do cacho } \\
(\mathrm{kg})\end{array}$ & $\begin{array}{c}\text { Produtividade de } \\
\text { cachos } \\
\left(\mathrm{Mg} \mathrm{ha}^{-1}\right)\end{array}$ \\
\hline $\mathrm{CC}$ & 6,9 & $124 \mathrm{a}$ & 12,74 & 16,98 \\
$\mathrm{SC}$ & 7,0 & $116 \mathrm{ab}$ & 13,25 & 17,66 \\
\hline
\end{tabular}

Médias seguidas das mesmas letras não diferem entre si pelo teste de Tukey a 5\% de significância.

As médias de produtividade de cachos de banana encontradas neste trabalho, são superiores as obtidas por Arantes et al. (2017) e menores que as apresentadas por Roque et al. (2014) para outras cultivares do tipo maçã, considerando a densidade de plantio utilizada no presente trabalho (1.333 plantas $\mathrm{ha}^{-1}$ ). Salienta-se que a produtividade média encontrada, de aproximadamente $17 \mathrm{Mg} \mathrm{ha}^{-1}$, está acima da média nacional de $14,34 \mathrm{Mg} \mathrm{ha}^{-1}$ (FAO, 2019).

A qualidade físico-química das frutas de banana também não foi influenciada pela aplicação das lâminas ou uso da cobertura morta. Registraram-se médias de número de frutos por penca: 16,32 frutos; massa da segunda penca: $1.304,12 \mathrm{~g}$; massa de fruto: $79,25 \mathrm{~g}$; comprimento do fruto de: $13,98 \mathrm{~cm}$; diâmetro de fruto: $3,35 \mathrm{~cm}$; percentagem de massa seca e de água na polpa: 27,39 e 71,93 $\%$, respectivamente; acidez total titulável: 0,1875\%; sólidos solúveis totais: $20,69^{\circ} \mathrm{Brix}$; pH da polpa: 4,41 ; índice de maturação (Ratio): 116,50 .

As médias registradas para as variáveis de qualidade dos frutos estão próximas ou diferem muito pouco daquelas divulgadas por Ribeiro et al. (2012), que avaliaram as possíveis diferenças de qualidade dos frutos da BRS
'Tropical' em condição de cultivo orgânico e convencional, também no Município de Cruz das Almas-BA.

A despeito dos resultados encontrados serem próximos a outros autores que trabalharam em condições parecidas com a 'BRS Tropical', esperava-se um desempenho inferior das plantas que receberam menor oferta de água, uma vez que houve um período de déficit hídrico, com chuvas concentras em poucos dias, entre outubro de 2010 e abril de 2011. Neste período, que se estendeu do fim do estádio juvenil ao início da floração, as plantas passavam por estádios fenológicos sensíveis a falta de água no solo, com reflexos conhecidos sobre a produtividade de cachos da bananeira (DONATO et al., 2017).

A Figura 1 apresenta a distribuição mensal acumulada das chuvas e da necessidade de irrigação calculada (100\%ETc), durante o experimento. A Figura 2 ilustra a evapotranspiração da cultura e as lâminas de irrigação aplicadas por nível de irrigação. As lâminas totais aplicadas dos níveis de irrigação foram de $431,4 \mathrm{~mm}$ para a L1, 323,5 $\mathrm{mm}$ para a L2 e 215,7 mm para a L3. Essas lâminas corresponderam, $31,83 \%, 23,87 \%$ e $15,91 \%$, respectivamente, da precipitação total do período, que foi da ordem de 1.355,0 $\mathrm{mm}$. 
Amorim et al.

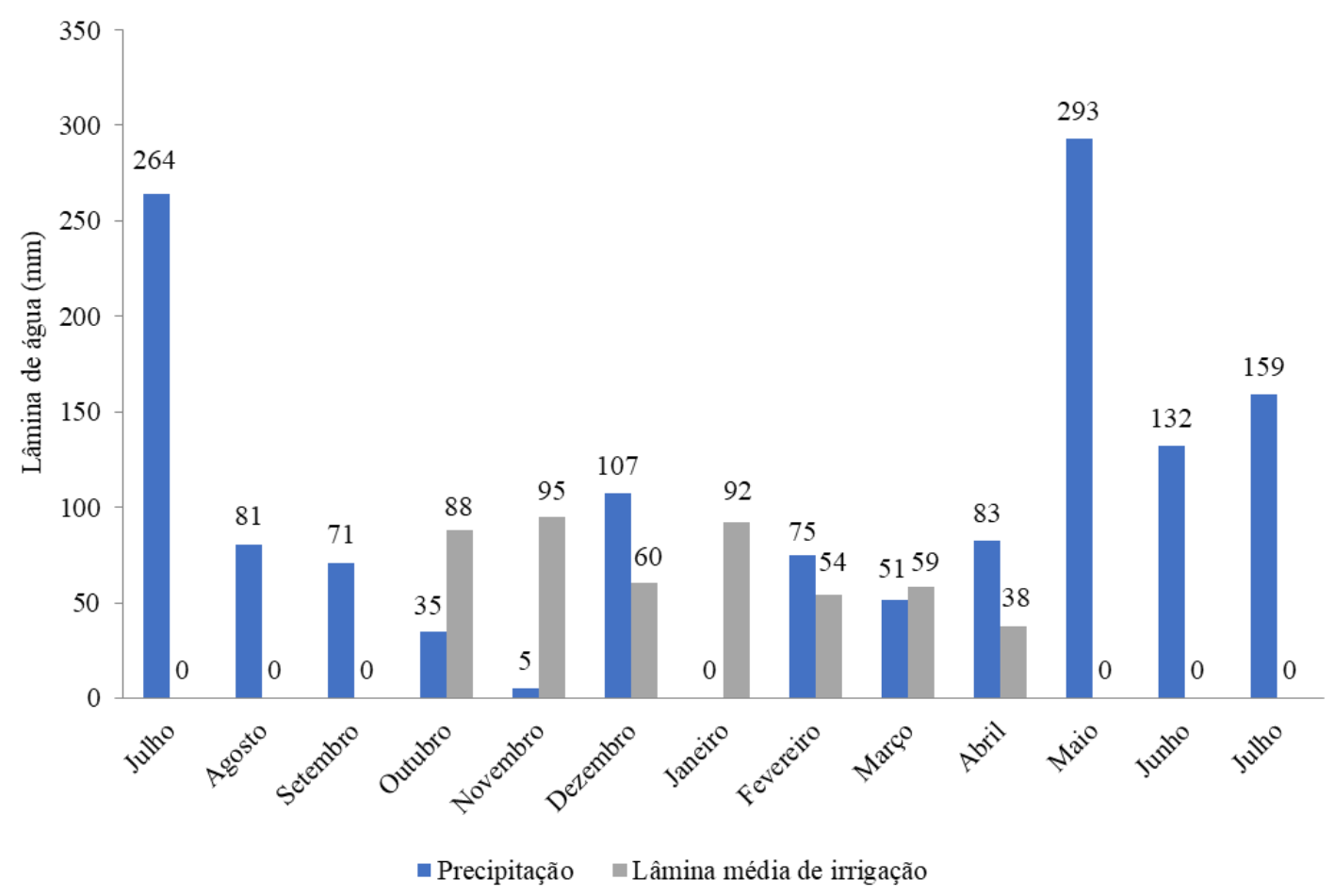

Figura 1. Distribuição mensal acumulada das chuvas e da necessidade de irrigação calculada (100\%ETc), durante o ciclo de produção da bananeira, entre julho de 2010 e julho de 2011 no município de Cruz das Almas - BA.

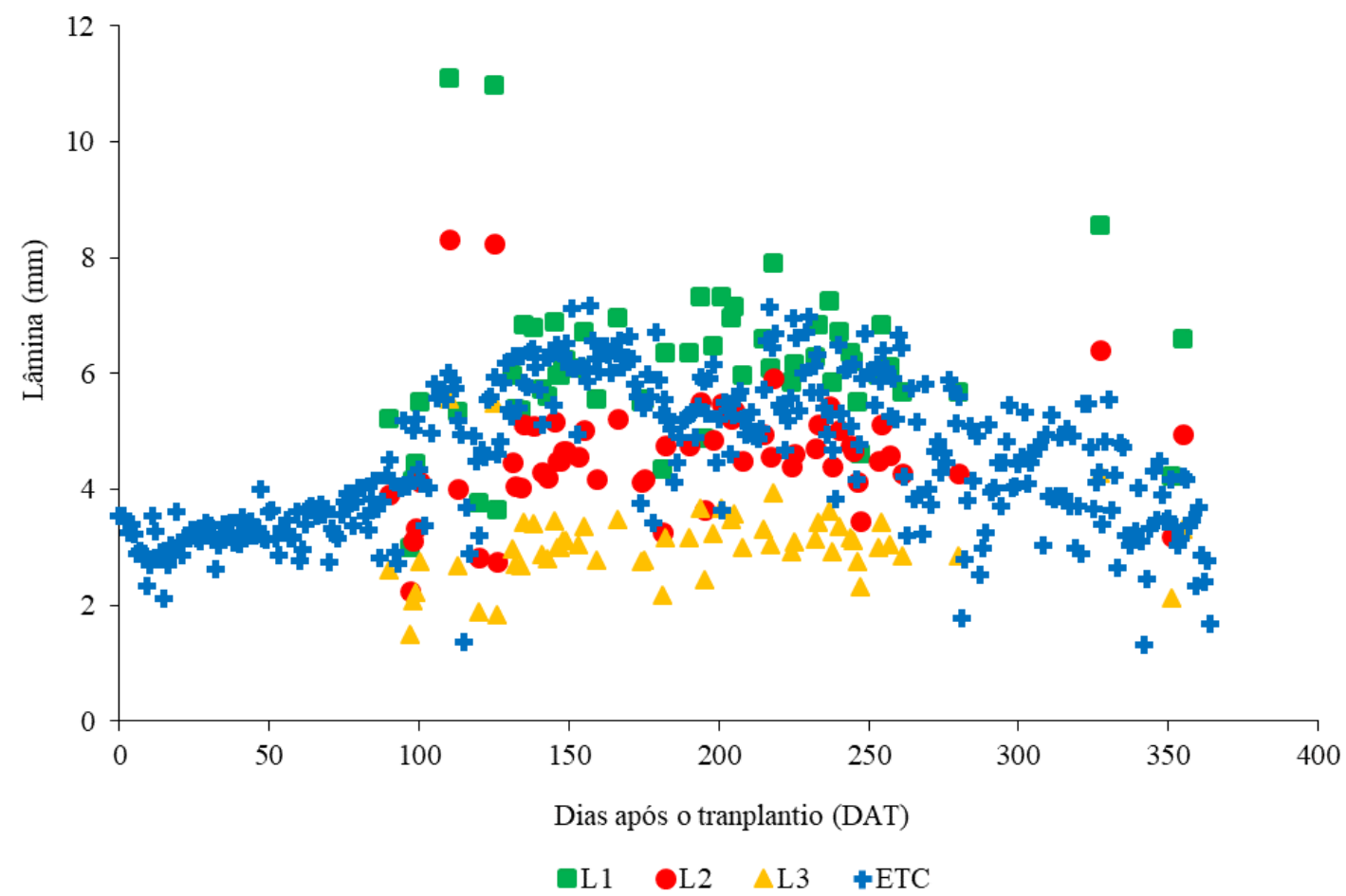

Figura 2. Lâminas de água referente à evapotranspiração e lâminas de irrigação calculadas por tratamento, entre julho de 2010 e julho de 2011 em um Latossolo Amarelo no município de Cruz das Almas - BA. 
A restrição hídrica registrada no período de sensibilidade a falta de água no solo indica que a cultivar BRS Tropical pode apresentar algum nível de tolerância ao déficit hídrico ou baixa resposta a irrigação. Resultados parecidos foram reportados por Coelho et al. (2009) que apresentaram que a redução de até $90 \%$ da lâmina de irrigação total calculada não influenciou na produtividade da 'BRS Tropical', também em Cruz das Almas-BA.

Apesar de não terem sido identificados efeitos sobre a produtividade ou qualidade dos frutos, foram verificados efeitos isolados das lâminas de irrigação e cobertura morta sobre a disponibilidade média de água no solo, da condução orgânica sobre os atributos físicos do solo e da cobertura morta sobre os atributos químicos.

O uso da cobertura morta promoveu maior disponibilidade da água no solo no tempo, assim como o incremento dos níveis das lâminas de irrigação. As médias da umidade a 0,30 $\mathrm{m}$ de profundidade nas condições de solo nu foram $0,225 \mathrm{~cm}^{3} \mathrm{~cm}^{-3}$ para a L1 $(100 \% \mathrm{da}$ ETc), $0,197 \mathrm{~cm}^{3} \mathrm{~cm}^{-3}$ para a L2 (75\% da ETc) e $0,155 \mathrm{~cm}^{3} \mathrm{~cm}^{-3}$ para a L3 (50\% da ETc). Na condição de uso de cobertura morta as umidades médias a $0,30 \mathrm{~m}$ de profundidade foram de 0,$299 ; 0,237 \mathrm{e} 0,227 \mathrm{~cm}^{3} \mathrm{~cm}^{-3}$ para as lâminas L1, L2 e L3, respectivamente.

A cobertura morta tem um papel conhecido na proteção do solo e na conservação da água (SOUZA; BORGES, 2016). Cobrir o solo com restos culturais proporciona redução da amplitude térmica, protege a superfície do solo da radiação solar direta e tende a proporcionar incrementos nos teores de matéria orgânica do solo, o que pode trazer uma série de benefícios sobre sua estrutura e capacidade de armazenamento de água (RESENDE et al., 2005; BORGES et al., 2015).

Os efeitos da condução orgânica sobre os atributos físicos do solo foram registrados aos 200 dias após o início do experimento, quando foi verificado um aumento da macroporosidade média de 2,99 para 7,18\%, com aumento real da porosidade total média do solo de 31,63 para $35,60 \%$, sem alterações na microporosidade. O incremento da porosidade total proporcionou um tênue decréscimo da densidade aparente de 1,73 para $1,60 \mathrm{~g} \mathrm{~cm}^{-3}$. Aos 400 DAT, não foram verificadas diferenças significativas em relação aos valores dos atributos físicos do solo verificados aos 200 DAT (Tabela 3).

Tabela 3. Atributos físicos médios de todos os tratamentos analisados em função do tempo para camada do solo entre 0,00-0,20 m em um Latossolo Amarelo no município de Cruz das Almas - BA.

\begin{tabular}{ccccc}
\hline $\begin{array}{c}\text { Tempo } \\
(\text { dias })\end{array}$ & $\begin{array}{c}\text { Macroporosidade } \\
(\%)\end{array}$ & $\begin{array}{c}\text { Microporosidade } \\
(\%)\end{array}$ & $\begin{array}{c}\text { Porosidade Total } \\
(\%)\end{array}$ & $\begin{array}{c}\text { Dens. aparente } \\
\left(\mathrm{g} \mathrm{cm}^{-3}\right)\end{array}$ \\
\hline 0 & $2,99 \mathrm{a}$ & $28,27 \mathrm{a}$ & $31,63 \mathrm{a}$ & $1,73 \mathrm{~b}$ \\
200 & $7,18 \mathrm{~b}$ & $28,46 \mathrm{a}$ & $35,60 \mathrm{~b}$ & $1,60 \mathrm{a}$ \\
400 & $7,33 \mathrm{~b}$ & $28,64 \mathrm{a}$ & $35,64 \mathrm{~b}$ & $1,63 \mathrm{a}$ \\
\hline
\end{tabular}

Médias seguidas das mesmas letras não diferem entre si pelo teste de Tukey a 5\% de significância.

O incremento da macroporosidade e redução da densidade aparente indicam o efeito positivo do manejo orgânico com aplicação de biofertilizantes, visto que o mesmo beneficia a estrutura do solo, melhorando a agregação.

A aplicação de biofertilizantes pode promover a melhoria dos atributos físicos do solo, tornando os solos mais soltos e estruturados (ALENCAR et al., 2015).

Além disso, os ácidos orgânicos podem afetar positivamente a atividade radicular da bananeira, enquanto a decomposição da matéria orgânica pode potencializar a ação dos organismos formadores de bioporos e a ciclagem de nutrientes (BALDOTTO; BALDOTTO, 2014; BORGES et al., 2015; COELHO et al., 2016).

Aos 400 DAT, foi registrado que o uso da cobertura morta, quando comparado ao solo nu na camada de solo entre 0 e $0,20 \mathrm{~m}$, proporcionou aumento no conteúdo de nutrientes no solo, com incremento nos conteúdos de fósforo, potássio, cálcio e magnésio no solo. Além disso, houve redução da acidez potencial e incremento do teor de matéria orgânica. 
Ao avaliar os resultados do teste de Tukey (Tabela 4) para a análise química inicial do solo e aos 400 DAT, com e sem o uso de cobertura morta, verificou-se que ao final do ciclo de produção houve um incremento no conteúdo de fósforo, magnésio e teores de matéria orgânica. Entretanto, houve maior acúmulo quando foi utilizada a cobertura morta, que também proporcionou incremento no conteúdo de potássio.

com Os teores de cálcio caíram cobertura, com maior decréscimo para o solo nu. A acidez potencial aumentou ao final do ciclo de produção, com maior incremento para o solo nu.

Tabela 4. Média dos atributos químicos do solo analisados no início do experimento (avaliação 0) e em função da cobertura (com cobertura - CC e sem cobertura - SC) aos 400 DAT, na camada de 0 e 0,20 m de profundidade em um Latossolo Amarelo no município de Cruz das Almas - BA.

\begin{tabular}{cccccccc}
\hline $\begin{array}{c}\text { Cobertura do } \\
\text { solo }\end{array}$ & $\begin{array}{c}\mathrm{pH} \\
(\mathrm{em} \text { água })\end{array}$ & $\begin{array}{c}\mathrm{P}^{1} \\
\left(\mathrm{mg} \mathrm{dm}^{-3}\right)\end{array}$ & $\begin{array}{c}\mathrm{K}^{1} \\
\ldots \ldots \ldots \ldots \ldots \ldots \ldots . .\left(\mathrm{cmol}_{\mathrm{c}} \mathrm{dm}^{-3}\right) \ldots \ldots \ldots \ldots \ldots \ldots \ldots \ldots\end{array}$ & $\begin{array}{c}\mathrm{MO} \\
\mathrm{g} \mathrm{kg}^{-1}\end{array}$ \\
\hline $\mathrm{CC}$ & 6,19 & $79,88 \mathrm{a}$ & $0,37 \mathrm{a}$ & $1,91 \mathrm{~b}$ & $1,60 \mathrm{a}$ & $2,20 \mathrm{~b}$ & $10,39 \mathrm{a}$ \\
$\mathrm{SC}$ & 5,86 & $39,50 \mathrm{~b}$ & $0,17 \mathrm{~b}$ & $1,63 \mathrm{c}$ & $1,30 \mathrm{~b}$ & $3,02 \mathrm{a}$ & $9,20 \mathrm{~b}$ \\
Avaliação 0 & 5,98 & $12,00 \mathrm{c}$ & $0,12 \mathrm{~b}$ & $2,22 \mathrm{a}$ & $1,11 \mathrm{~b}$ & $1,55 \mathrm{c}$ & $1,68 \mathrm{c}$ \\
\hline
\end{tabular}

Médias seguidas das mesmas letras não diferem entre si pelo teste de Tukey a 5\% de significância. P: fósforo K: potássio; Ca: cálcio; Mg: magnésio; MO: teor de matéria orgânica; $\mathrm{H}+\mathrm{Al}$ : acidez potencial; $\mathrm{P}, \mathrm{K}$ e Al extraídos com solução Mehlich1; Ca e Mg extraídos com solução de $\mathrm{KCl} 1 \mathrm{~mol} \mathrm{~L}^{-1}$.

É normal observar o aumento na disponibilidade de nutrientes, em especial o $\mathrm{P}$ no solo com o incremento nos teores de matéria orgânica. Esse efeito ocorre ora pela ciclagem do $\mathrm{P}$ presente nos resíduos, ora por competição de compostos orgânicos originados do material orgânico pelos sítios de troca de íons que podem se associar ao $\mathrm{P}$ e deixa-lo indisponível na solução do solo (BALDOTTO; BALDOTTO, 2014).

Em complemento, Pavinato e Rosolem (2008) explicam que a adição de resíduos vegetais pode promover, antes da humificação, a elevação do $\mathrm{pH}$, por promover a complexação de $\mathrm{H}$ e $\mathrm{Al}$ com compostos orgânicos do resíduo vegetal, deixando $\mathrm{Ca}, \mathrm{Mg}$ e $\mathrm{K}$ mais disponíveis para as plantas.

As reduções de cálcio entre o início e fim do ciclo de produção confirmam e justificam a elevada demanda das plantas pelo nutriente e o tênue acréscimo da acidez potencial em função da extração dessas bases da solução do solo.

$\mathrm{O}$ incremento mais acentuado dos conteúdos de potássio e magnésio no tratamento com cobertura morta se deve a incorporação dos nutrientes presentes nos restos culturais da bananeira, como apresentado por Borges et al. (2015).

As diferenças registradas entre o solo nu e recoberto com os resíduos culturais da bananeira confirmam que a cobertura orgânica do solo com resíduos culturais pode ser uma estratégia para melhorar o conteúdo de nutrientes do solo e conservar a água. Além disso, os resultados encontrados para 'BRS Tropical' demonstram que a variedade pode apresentar algum nível de tolerância ao déficit hídrico, sendo necessário o aprofundamento das investigações para avaliar e confirmar essa característica frente condições de estresse mais severas.

\section{CONCLUSÕES}

O uso de cobertura morta, quando comparado ao cultivo em solo nu ao final do ciclo de produção, influenciou positivamente na disponibilidade média de água do solo, no conteúdo de fósforo, potássio, cálcio e magnésio no solo. Além disso, proporcionou redução da acidez potencial e incremento no teor de matéria orgânica.

A condução orgânica do cultivo com aplicação de biofertilizantes proporcionou aumento da macroporosidade, porosidade total e redução da densidade aparente do solo.

O desempenho da cultivar BRS Tropical não foi afetada pela redução em até $50 \%$ da lâmina de irrigação aplicada ou pelo uso da cobertura morta. 


\section{AGRADECIMENTOS}

A Coordenação de Aperfeiçoamento de Pessoal de Nível Superior (CAPES), Conselho Nacional de Desenvolvimento Científico e Tecnológico (CNPQ) e Fundação de Amparo à Pesquisa do Estado da Bahia (FAPESB) pelos recursos financeiros utilizados pelos bolsistas de pós-graduação e no fomento à pesquisa. A Embrapa pelo suporte técnico, concessão da área experimental, recursos humanos $\mathrm{e}$ financeiros.

\section{REFERÊNCIAS BIBLIOGRÁFICAS}

ALENCAR, T. L.; CHAVES, A. F.; SANTOS, C. L. A; ASSIS JÚNIOR, R. N.; MOTA, J. C. A. Atributos físicos de um Cambissolo cultivado e tratado com biofertilizante na Chapada do Apodi, Ceará. Revista Brasileira de Ciência do Solo, v. 39, n. 3, 2015. https://dx.doi.org/10.1590/01000683rbcs2014 0437

ALLEN, R. G.; PEREIRA, L. S.; RAES, D.; SMITH, M. Crop evapotranspirationguidelines for computing crop water requirements. Roma: FAO Irrigation and Drainage $\mathrm{n}^{\circ} 56,1998,300 \mathrm{p}$.

ARANTES, A. D.; DONATO, S. L. R.; SILVA, T. S.; RODRIGUES FILHO, V. A.; AMORIM, E. P. Agronomic evaluation of banana plants in three production cycles in southwestern state of Bahia. Revista Brasileira de Fruticultura, v. 39, n. 1, e-990, $2017 . \quad$ http://dx.doi.org/10.1590/010029452017990

ARAUJO, J. L P.; COELHO, R. C.; SOUZA, I. C. M. Custo de produção da banana orgânica, no Vale do Submédio São Francisco, no Estado da Bahia. Revista Sodebras, v. 11, n. 127, 2016.

BALDOTTO, M. A.; BALDOTTO, L. E. B. Ácidos húmicos. Revista Ceres, v. 61, n. 7, p. 856-881, 2014. http:// dx.doi.org/10.1590/0034 - 737x201461000011
BEZERRA A. E.; OLIVEIRA C. W.; MORAIS NETO, J. M.; SILVA, T. I.; MEIRELES, A. C. M.; SANTOS, H. R. dos. Eficiência do uso da água de irrigação no cultivo de banana (Musa sp. L.). Revista Brasileira de Agricultura Irrigada, v. 11, n. 7, p. 1966-1974, 2017. http://dx.doi.org/10.7127/rbai.v11n700663

BORGES, A. L.; CORDEIRO, Z. J. M.; FRANCELLI, M.; RODRIGUES, M. G. V. Bananicultura orgânica. Informe Agropecuário, v. 36, n. 287, p. 74-83, 2015.

BRASIL. Lei no 10.831, de 23 de dezembro de 2003. Dispõe sobre a agricultura orgânica e dá outras providências. Diário Oficial da República Federativa do Brasil, Brasília, 24 dez. 2003.

BRASIL. Ministério da Agricultura, Pecuária e Abastecimento. Instrução Normativa no 46, de 6 de outubro de 2011. Estabelece o Regulamento Técnico para os Sistemas Orgânicos de Produção, bem como as listas de substâncias e práticas permitidas para uso nesses sistemas, na forma desta Instrução Normativa e de seus Anexos I a VIII. Diário Oficial da República Federativa do Brasil, Brasília, 7 out. 2011. Seção 1.

BRASIL. Ministério da Agricultura, Pecuária e Abastecimento. Instrução Normativa $\mathrm{n}^{\circ} 17$, de 18 de junho de 2014. Altera os arts. 10, 20, 30, $80,13,14,15,20,21,29,34,35,38,39,42,59$, $60,63,80,81,82,85,89,100,101,103,106$, 108 , todos da Instrução Normativa ${ }^{\circ} 46$, de 6 de outubro de 2011. Diário Oficial da República Federativa do Brasil, Brasília, 20 jun. 2014. Seção 1.

COELHO, E. F.; COSTA, E. L.; TEIXEIRA, A. H. C.; OLIVEIRA, S. L. Irrigação da bananeira. Circular técnica, n. 53, 8p. Cruz das Almas: Embrapa Mandioca e Fruticultura Tropical, 2003.

COELHO, E. F.; MELO, D. M.; PEREIRA, B. L. S.; SANTOS, D. B.; ROSA, R. C. C. Roots of 'BRS Princesa' banana fertigated with 
humic substances and saponin-based plant extracts. Acta Scientiarum Agronomy, v. 38, n. $4, \quad$ p. 521-528, 2016. http://dx.doi.org/10.4025/actasciagron.v38i4.3 0790

COELHO, E. F.; SILVA, A. J. P. Irrigação da bananeira. In: FERREIRA, C. F. et al. (Org.). $O$ agronegócio da banana. 1. ed. Brasília: Embrapa, 2016, p. 773-810.

COELHO, E. F.; PAMPONET, A. J. M.; NASCIMENTO JUNIOR, A. L.; COELHO FILHO, M. A.; SANTANA JUNIOR, E.B. Redução da irrigação e efeito na produtividade de bananeira BRS Tropical nos tabuleiros costeiros. In: XXXVIII Congresso Brasileiro de Engenharia Agrícola, 2009, Juazeiro (BA) Petrolina (PE). Anais. Planejamento da Bacia Hidrográfica e o Desenvolvimento da Agricultura, 2009.

DONATO, S. L. R.; ARANTES, A. M.; RODRIGUES FILHO, V. A.; RODRIGUES, M. G. V.; RODRIGUES, F. E. Aspectos de ecofisiologia e estratégias de manejo da bananeira. In: ZUCOLOTO, M.; BONOMO, R. (Org.). Fruticultura tropical: diversificação e consolidação. Alegre: CAUFES, 2017, p. 57-73.

EMBRAPA. Manual de métodos de análise de solo. 2. ed. Rio de Janeiro: Centro Nacional de Pesquisa de Solos, 1997. 212p.

FAO - Food and Agriculture Organization of the United Nations. FAOSTAT: Food and agriculture data. Disponível em: <http://www.fao.org/faostat/en/\#data/QC >. Acesso em: 13 jun. 2019.

IBGE. Produção Agrícola Municipal em 2017. Produção Agrícola Municipal: Culturas Temporárias e Permanentes. Rio de Janeiro: IBGE, v. 44, 2018, 8p.

FRIZZONE, J. A. Planejamento da irrigação com uso de técnicas de otimização. Revista Brasileira de Agricultura Irrigada, v. 1, n. 1, 2007.
IAL - INSTITUTO ADOLFO LUIZ. Métodos físico-químicos para análise de alimentos, 4ed. Brasília: Ministério da Saúde, 2005.

PAVINATO, P. S.; ROSOLEM, C. A. Disponibilidade de nutrientes no solo: decomposição e liberação de compostos orgânicos de resíduos vegetais. Revista Brasileira de Ciência do Solo, Viçosa, v. 32, n. $3, \quad$ p. $911-920, \quad 2008$ http://dx.doi.org/10.1590/S010006832008000300001

RESENDE, F. V.; SOUZA, L. S.; OLIVEIRA, P. S. R.; GUALBERTO, R. Uso de cobertura morta vegetal no controle da umidade e temperatura do solo, na incidência de plantas invasoras e na produção da cenoura em cultivo de verão. Revista Ciência e Agrotecnologia, Lavras, v. 29, n. 1, p. 100-105, 2005. http://dx.doi.org/10.1590/S1413-

70542005000100012

RIBEIRO, L. R.; OLIVEIRA, L. M.; SILVA, S. O.; BORGES, A. L. Caracterização física e química de bananas produzidas em sistemas de cultivo convencional e orgânico. Revista Brasileira de Fruticultura, v. 34, n. 3, p. 774782, 2012.

ROEL, A. R. A agricultura orgânica ou ecológica e a sustentabilidade da agricultura. Interações, v. 3, n. 4, 2016.

ROQUE, R. L.; AMORIM, T. B.; FERREIRA, C. F.; LEDO, C. A. S.; AMORIM, E. P. Desempenho agronômico de genótipos de bananeira no recôncavo da Bahia. Revista Brasileira de Fruticultura, v. 36, n. 3, p. 598609 , 2014. http://dx.doi.org/10.1590/01002945-361/13.

SANTOS, J. O.; SANTOS, R. M. S.; BORGES, M. G. B.; FERREIRA, R. T. F. V.; SALGADO, A. B.; SANTOS SEGUNDO, O. A. A evolução da agricultura orgânica. Revista Brasileira de Gestão Ambiental, v. 6, n. 1, p. 35-41, 2013.

SANTOS, H. G. dos; JACOMINE, P. K. T.; ANJOS, L. H. C. dos; OLIVEIRA, V. A. de; 
LUMBRERAS, J. F.; COELHO, M. R.; ALMEIDA, J. A. de; ARAUJO FILHO, J. C. de; OLIVEIRA, J. B. de; CUNHA, T. J. F.(Eds.) Sistema brasileiro de classificação de solos. 5. ed. rev. ampl. Brasília: Embrapa, 2018. 356 p.

SEDIYAMA, M. A. N.; SANTOS, I. C.; LIMA, P. C. Cultivo de hortaliças no sistema orgânico. Revista Ceres, v. 61, n. 7, 2015. http://dx.doi.org/10.1590/0034-

$737 \times 201461000008$

SILVA, S. O.; AMORIM, E. P.; SANTOSSEREJO, J. A.; FERREIRA, C. F.; RODRIGUEZ, M. A. D. Melhoramento genético da bananeira: estratégias e tecnologias disponíveis. Revista Brasileira de Fruticultura, v. 35, n. 3, p. 919-931, 2013. http://dx.doi.org/10.1590/S0100-

29452013000300032

SOUZA, L. S.; BORGES, A. L. Solo manejo e conservação. In: FERREIRA, C. F. et al.
(Org.). O agronegócio da banana. $1^{\mathrm{o}}$ ed. Brasília: Embrapa, 2016, p. 277-330. VAIRO, A. C. S.; AKIBA, F. Biofertilizante líquido: uso correto na agricultura alternativa. Seropédica: Imprensa Universitária, 1996, 35 p.

VEIRA, E. T. V.; GUILHERME, D. O.; ITAVO, L. C. V.; TASHIMA, L. C. Agricultura orgânica: solução para o século XXI?. Revista Brasileira Políticas Públicas, v. 6, n. 2, p. 184-202, 2016. http://dx.doi.org/10.5102/rbpp.v6i2.3973

WEBER, O. B.; GARRUTI, D. S.; NORÕES, N. P.; SILVA, S. O. Desempenho de genótipos de bananeira com resistência à sigatoka - negra no Nordeste brasileiro. Pesquisa Agropecuária Brasileira, Brasília, v. 52, n. 3, p. 161-169, $2017 \mathrm{http}: / / \mathrm{dx}$.doi.org/10.1590 S0100- 204X2017000300003 